\title{
Controls on burial of sedimentary organic carbon in the Eastern China Marginal Seas: A Regional synthesis
}

\author{
P. YAO ${ }^{1,2}$, B. ZHAO ${ }^{1}$, T. S. BIANCHI ${ }^{3}$, Z. G. YU ${ }^{1,2}$ \\ ${ }^{1}$ Key Laboratory of Marine Chemistry Theory and \\ Technology, Ministry of Education/Institute for \\ Advanced Ocean Study, Ocean University of China, \\ Qingdao, China
}

${ }^{2}$ Laboratory for Marine Ecology and Environmental Science, Qingdao National Laboratory for Marine Science and Technology, Qingdao, China

${ }^{3}$ Department of Geological Sciences, University of Florida, Gainesville, USA

Marginal seas are usually characterized by contrasting sedimentary environments, which may greatly influence the burial of sedimentary OC (SOC). We measured grain-size composition, sediment surface area (SSA), total OC (TOC), stable carbon isotopic composition $\left(\delta^{13} \mathrm{C}\right)$, lignin phenols and pigments in ECMS sediments to investigate the oxidation and burial of SOC within the Eastern China Marginal Seas (ECMS, including Bohai Sea (BS), Yellow Sea (YS) and East China Sea (ECS)). Data (including radiocarbon isotopic composition $\left(\Delta^{14} \mathrm{C}\right)$ and reactive iron combined $\left.\mathrm{OC}\right)$ of suspended particulate matters (SPM) from the Changjiang and Yellow River and/or ECMS sediments in literatures were integrated and/or assimilated. Results of an end-member mixing model, based on $\delta^{13} \mathrm{C}$ and lignin contents, showed that marine $\mathrm{OC}$ is the major source of $\mathrm{OC}$ in the ECMS, accounting for $63.2 \pm 10.8 \%$. Both TOC and $\Delta{ }^{14} \mathrm{C}$ values in Changjiang SPM were significantly higher than those in the Changjiang Estuary mud area (CEMA) sediments (1.21 \pm $0.21 \%$ vs. $0.53 \pm 0.08 \%$ and $-114.3 \pm 10.9 \%$ vs. $-362.1 \pm$ $49.6 \%$, respectively), indicating that a large part of young terrestrial OC is decomposed during sediment deposition. However, TOC continuously increased from Yellow River SPM to Central Yellow Sea mud area (CYSMA) sediments with the increase of $\delta^{13} \mathrm{C}$ and $\Delta^{14} \mathrm{C}$ values, indicating continue inputs of young marine OC. The OC burial efficiency in mud areas in the BS $(\sim 44.4 \%)$ was higher than those in the YS $(\sim 10.8 \%)$ and ECS $(\sim 15.9 \%)$. Large difference of burial efficiencies between marine $(\sim 7.3 \%)$ and terrestrial $\mathrm{OC}$ $(\sim 45.3 \%)$ in CYSMA were largely attributed to the inputs of pre-aged terrestrial OC and long-term transport of marine OC caused by cyclonic cold eddies. Our findings suggest that complex sedimentary environments greatly influenced decomposition and burial efficiencies of OC from different sources in mud areas of the ECMS. 